\section{$\underset{\substack{\text { hommes } \\ \text { \& migrations }}}{ }$}

\section{Hommes \& migrations}

Revue française de référence sur les dynamiques

migratoires

$1331 \mid 2020$

Femmes engagées

\title{
Salomé Berlemont-Gilles, Le premier qui tombera
}

Paris, Grasset, 2020, 288 p., $19 €$.

\section{Mustapha Harzoune}

\section{(2) OpenEdition}

\section{Journals}

\section{Édition électronique}

URL : https://journals.openedition.org/hommesmigrations/12017

DOI : 10.4000/hommesmigrations. 12017

ISSN : 2262-3353

\section{Éditeur}

Musée national de l'histoire de l'immigration

\section{Édition imprimée}

Date de publication : 17 novembre 2020

Pagination : 231-232

ISBN : 978-2-919040-52-0

ISSN : $1142-852 X$

\section{Référence électronique}

Mustapha Harzoune, "Salomé Berlemont-Gilles, Le premier qui tombera », Hommes \& migrations [En ligne], 1331 | 2020, mis en ligne le 01 novembre 2020, consulté le 06 janvier 2023. URL : http:// journals.openedition.org/hommesmigrations/12017; DOI : https://doi.org/10.4000/ hommesmigrations.12017 


\section{Livres}

\section{Le premier qui tombera}

Salomé Berlemont-Gilles, Paris, Grasset, 2020, 288 p., $19 €$.

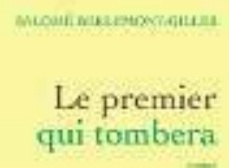

Le premier qui tombera

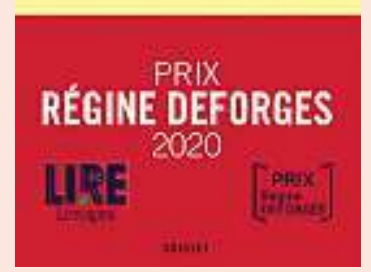


Tout commence dans une chambre d'hôpital. Les histoires d'exil aussi finissent mal. Parfois. Pour les uns, il est renaissance, pour les autres, un long couloir, sombre et froid, l'antichambre de la mort.

Hamadi avait 11 ans lorsque sa famille a fui Conakry, la grande maison, son personnel, le luxe et la bonne éducation. Le père «le Chirurgien» est "fier d'être un homme noir dans le quartier des Blancs». Hamadi est le chouchou de Marie, sa mère, belle et insouciante. Mais, dans la Guinée de Sékou Touré, à l'instar de bien des indépendances africaines, le nouveau pouvoir fanfaronne et endort le populo à coups de slogans anti-impérialistes, de nationalisme chauvin et d'ennemis intérieurs. Ici, les Peuls tiennent le rôle de "bouc émissaire des douleurs du pays». Dans la voiture qui emporte la famille, Marie, «la tête tournée vers la fenêtre, pleure». L'exil commence par des pleurs, de la peur, de la honte.

40 ans plus tard, sur un lit d'hôpital, Hamadi a honte. Encore. Il n'est plus qu'«un noud de honte». Ses frères et sœurs sont «dans la salle d'attente, au milieu des clochards et des parents angoissés, ils portent ensemble la blessure de l'échec. [...] Ils sont seuls. L'aîné de l'autre côté de la porte est un héros que la vie a condamné et qui n'a rien fait pour se battre». Entre cette scène inaugurale et la fuite, il y a 40 ans d'exil d'une famille pourvue, au départ, de solides atouts : père chirurgien, mère éduquée, des économies pour voir venir et cette volonté - paternelle - de faire de la France leur nouveau pays et de l'école l'outil de la réussite. Tout sera pourtant insuffisant: les diplômes du père ne valant rien, Marie accepte de travailler comme caissière dans un supermarché. Les économies sont englouties à la va-vite dans un modeste appartement d'une cité à Bobigny. L'école? Elle sera source de déceptions, notamment pour les garçons. À commencer par Hamadi, celui sur qui le Chirurgien avait placé trop d'espoirs.

Hamadi croyait devenir le protecteur de ses frères et sœurs ; il va faire l'école buissonnière et rallier la bande de La Fraternité, il y trouve "les clefs d'une désintégration réussie». 22 ans, Hamadi devient «gardien de putes». Hamadi est un naïf qui croit au paradis dans l'enfer de la prostitution mondialisée. Hamadi est un puceau doublé d'un jocrisse, il commence par désirer Khadijah, avant d'enfreindre la règle de cet "empire de foutre et de sang»: "baiser oui, mais pas d'histoire d'amour». Hamadi commet l'erreur de trop. Un frangin paiera l'addition. Hamadi reste un mégalo, un brin irresponsable, qui croit que «lui ne sera pas comme son père, lui ne sera pas un esclave». Il continue de se bercer d'illusions mais, la culpabilité aidant, il les noie désormais dans l'alcool. "C'était donc ça le rêve français dont son père parlait. » Pas certain que le couplet servi en quatrième de couverture sur «le mensonge des mots inscrits au frontispice des bâtiments de notre République» soit pertinent. Pour Hamadi s'entend.

Le père "se demande si tout cela en valait la peine. Il pense à ses garçons, à la dérive qu'il n'a pas réussi à éviter». Il garde espoir ! Dans ce premier roman, Salomé Berlemont-Gilles décrit avec justesse et sensibilité les émotions, les attentes, les doutes, les craintes, les angoisses, la honte que cet homme "ressent à revenir dans un pays où il sent bien qu'il n'est plus le bienvenu. La violence du mot "immigré" pour celui qu'on nomme comme tel et qui cherche un refuge, la stupidité qu'ont certains à vouloir forcer l'autre à être de quelque part, comme si l'origine se mêlait au sang». Le Chirurgien se sent trahi par son fils mais ne lui dit pas «qu'il pensait qu'il serait le seul sacrifié, qu'il n'avait pas prédit qu'il perdrait son fils dans cette chute ordinaire». De silences en non-dits, le père et le fils s'éloignent. Marie, elle, tient. Debout. Marie pleure peu. Forte. Elle "est une femme sans regrets». Elle est le contrepoint psychologique du Chirurgien. Dans la tempête, le couple reste uni. Comme tente de le rester la fratrie.

M. H. 